\title{
Research on Application of Internet of Things Technology in Mold Management of Aluminum Profile Manufacturing Enterprises
}

\author{
Mingqiang Luo ${ }^{1, a^{*}}$, Cunxian Zou ${ }^{1, b}$ and Weihao Luo ${ }^{1, c}$ \\ ${ }^{1}$ Guangdong Xingfa Aluminium Co., LTD, Foshan, China \\ a8863200@qq.com, b285854774@qq.com, ‘490177840@qq.com \\ * The corresponding author
}

\begin{abstract}
Keywords: Aluminum profile mold; Internet of things; RFID; Direct part marking; Stereoscopic warehouse system
\end{abstract}

\begin{abstract}
There are many problems in mold management of aluminum profile manufacturing enterprises, such as huge variety and large space, low management efficiency and so on. In this paper, various marking technologies of aluminum profile mold under high temperature environment are analyzed. The methods of marking the aluminum profile mold by combining the traditional lettering mark with the DPM technology and fusing the bar code technology and the RFID technology are put forward. On this basis, combined with the existing Internet of things application framework and mold management function requirements, an open, layered, scalable mold management system framework based on the Internet of things is constructed. The framework consists of eight levels: information bearer layer, information collection layer, data transmission layer, data processing layer, core business function layer, integrated interface layer, user interface layer and data management layer. An automated stereoscopic warehouse system based on Internet of things and automatic control technology is also puts forward. The control system controls the stacker to finish the operation of the mold automatically according to the production requirement, while the computer management system achieves mold search, inventory and other work. It solves the problems such as data confusion, no chapter and difficult management of aluminum profile mold information.
\end{abstract}

\section{Introduction}

Extruded aluminum profiles have good properties such as light weight, high strength, good process ability and corrosion resistance. It has been widely used in aerospace, railway vehicles, automobiles and civil decorative materials. Extrusion forming is the most important production method of aluminum profile. Extrusion mold occupies a very important factor in the whole production process [1]. At present, large aluminum production enterprises have dozens of production lines. There are tens of thousands of sets of extrusion molds, and the molds used every day may reach thousands of sets. In the process of use and management of mold, at present, most enterprises use plane warehouse to store mold, and use bridge crane, forklift truck or manual way to transport. The classification, storage, transportation, storage and out of storage of the mold are very busy. The amount of logistics and labor intensity is particularly large. As the scale of production and product varieties continue to expand, the mold is also increasing. The original storage and supply mode cannot adapt to the production rhythm and management requirements. Overall, the current management of the mold mainly has the following problems [2][3[]4].

(1) The use of plane warehouse covers a large area, low land use efficiency, low space utilization.

(2) The handling workload and labor intensity are large, with more people, more time consuming, low efficiency and high labor cost.

(3) There are personal safety hazards in the process of artificial warehousing and transportation.

(4) Manual management prone to the wrong mold or cannot find the mold.

(5) The manual input of stock ledger is prone to error and leakage, and the efficiency is low. 
(6) It is difficult to implement modern management, inventory data and the company ERP system cannot be docked, warehousing information cannot be timely feedback to production, technology, finance, information center and other departments.

In order to solve the above problems, in view of the characteristics of aluminum profile extrusion die, this paper proposes to use the Internet of Things technology to manage the mold of aluminum profile manufacturing enterprises. The mold identification, RFID technology and DPM technology in mold management applications, mold three-dimensional automated warehouse construction and other aspects are researched and discussed.

\section{Mold Identification Technology}

There are four main mold identification technologies: traditional lettering marking technology, pasting barcode technology, RFID technology and DPM technology.

Traditional Lettering Marking Technology. The traditional method of mold identification is carved on the mold or graffiti characters and patterns. Usually the markings are rough. The method of identification is manual identification, and cannot be read by automatic equipment.

Pasting Barcode Technology. With the development of technology, researchers have added additional aluminum foil nameplate labels on the mold, and barcode technology is applied to the warehouse management of the mold. This can realize the automatic management of mold use. The simpler way is to use the printed paper bar code attached to the mold. One-dimensional bar code or two-dimensional bar code can be adopted. The main problem with using pasted barcode labels is that barcodes can be damaged in production and management and become unable to read. So the labels need to be regularly maintained. When the bar code has been damaged, it is necessary for the workers to read the lettering on the mold and print the corresponding barcode again.

RFID Technology. An anti-metal RFID tag is stick on each mold. The RFID tag information written mainly include: some important information such as mold number, product name, ownership and other static information, and the current state of mold, state changing time, location and other dynamic information. It also writes the updated data to the database server [6]. The most difficult problem of mold marking using RFID technology is the design of label. The working temperature of the mold is high, especially in the aluminum profile production enterprise, in the working state can reach above 400 degrees Celsius. So RFID tags can't always follow the mold together. Labels should be removed during production. It can only be used in warehouse and daily management. In addition, there are technical difficulties in the installation of tags due to the volume of tags. It is necessary to carry out targeted research on different molds.

DPM Technology. Direct part marking (DPM) is a process to permanently mark parts with product information including serial numbers, part numbers, date codes, and barcodes. This is done to allow the tracking of parts through the full life cycle. DPM is often used by automotive, aerospace, and electronic manufacturers to facilitate a reliable identification of their parts. This can assist in data logging for safety, warranty issues and satisfy regulatory requirements. DataMatrix two-dimensional bar code has become the most commonly used bar code type of DPM code. DataMatrix two-dimensional bar code has the characteristics of large coding capacity, high density and high information security.

Methods to produce a permanent mark on parts are: Indenting, Embossing, Coining, Abrasive blasting, Adhesive dispensing, Cast, forge or mold, Dot peen, Scribe, Electro-chemical etching, Embroidery, Engraving/milling, Laser marking, Laser Shot peening, Liquid metal jet, Stencil (mechanical cut, photo process, laser cut). Other methods like manual metal stamp, vibrio-etch and embossing were not suitable to successfully apply micro size, high density machine-readable symbols. Indenting, Embossing, and Coining are common methods for high speed marking of parts. Such as security seals, keys, small parts, and data tags. Specifically for man readable data, Laser, Scribe, and Dot Peen marking are incapable of keeping up with high volume production methods[7][8]. The factors that affect the readability of DMP codes include marking mode, marking position, marking quality, surface finish, comparison of unit size and element surface structure, component representation, element processing, and element geometry. 
Integration of Multiple Identification Technologies. Taking into account the various application scenarios, it is necessary to meet both the requirements of automatic identification and the cost factors and the difficulty of technical implementation. The marking technology of mold can adopt the scheme of multi mark technology integration as shown in table 1. Among them, the traditional lettering logo is indispensable. If the machine cannot read, artificial intervention and recognition is inevitable. For the case of using DPM technology, the traditional lettering logo and DPM can be completed together without the need for additional rework order.

Table 1 Fusion combination of mold marking technology

\begin{tabular}{|l|c|c|c|c|}
\hline $\begin{array}{l}\text { Single identification } \\
\text { technology }\end{array}$ & $\begin{array}{c}\text { Identification } \\
\text { combination 1 }\end{array}$ & $\begin{array}{c}\text { Identification } \\
\text { combination 2 }\end{array}$ & $\begin{array}{c}\text { Identification } \\
\text { combination 3 }\end{array}$ & $\begin{array}{c}\text { Identification } \\
\text { combination 4 }\end{array}$ \\
\hline $\begin{array}{l}\text { Traditional lettering marking } \\
\text { technology }\end{array}$ & $*$ & $*$ & $*$ & $*$ \\
\hline Pasting barcode technology & $*$ & $*$ & & $*$ \\
\hline RFID & & & $*$ & $*$ \\
\hline DPM & & $*$ & $*$ & $*$ \\
\hline
\end{tabular}

\section{Application Framework of Internet of Things in Aluminum Profile Mold Management}

While designing the mold management system architecture based on Internet of things technology, we should consider the function structure of the system itself, and also the integration with other systems within the enterprise. And this is helpful to solve the problem of "information isolated island" between systems and to realize the interconnection, intercommunication and interoperation of heterogeneous information [9]. Combined with the existing Internet of things application framework and mold management function requirements, an open, layered and extensible system framework is constructed. As shown in Fig. 1, the framework consists of eight levels: information bearer layer, information collection layer, data transmission layer, data processing layer, core business function layer, system application integration interface layer, user interface layer and data management layer. The framework focuses on the agility and informatization of extrusion mold management and control in aluminum production environment. It also pays attention to mold management at the workshop level of horizontal and vertical production integration and coordination.

Information Bearer Layer. Each new mold will have a unique ID or install an anti-metal RFID tag. Some characteristic information of mold, such as internal mold number, customer mold number, product number, mold ownership and other information through the ID or tag are associated with the mold. Therefore, each tag carries the basic information of the corresponding mold, which provides the basic guarantee for the operation of the whole system.

Information Collection Layer. The information collection layer mainly uses a variety of information collection devices, such as RFID reader, bar code reader, DPM reader, sensors, etc., to collect all kinds of state information of the mold and production line. A variety of physical quantities are converted into digital quantities that can be transmitted and processed.

Data Transmission Layer. Data transmission layer information transmit the data collected by the information collection layer to the corresponding terminal and data processing middleware through WIFI, 4G, LAN, ZigBee, Bluetooth and other wired and wireless network.

Data Processing Layer. By filtering and processing the collected information, the data processing layer processes the data collected from the information collection layer into functional information such as mold position information, mold status information and production status information.

Core Business Function Layer. Based on production information real-time feedback, the core business function layer realizes the production plan, and all kinds of mold warehouse management, maintenance management and mold production schedule monitoring and management.

System Application Integration Interface Layer. The system application integration interface layer mainly implements data sharing and service integration with other enterprise systems, such as 
enterprise resource planning (ERP), customer relationship management (CRM), product data management (PDM) and so on.

User Interface Layer. The user interface layer supports various information interaction modes such as PC, mobile terminal and so on, which facilitates the use of high-level personnel, workshop managers, team leaders and operators.

Data Management Layer. The real-time information collected by all terminal devices will be stored in the database server after the processing and integration of the mold management system. The data management layer is the overall planning and guarantee of the smooth operation of the whole system.

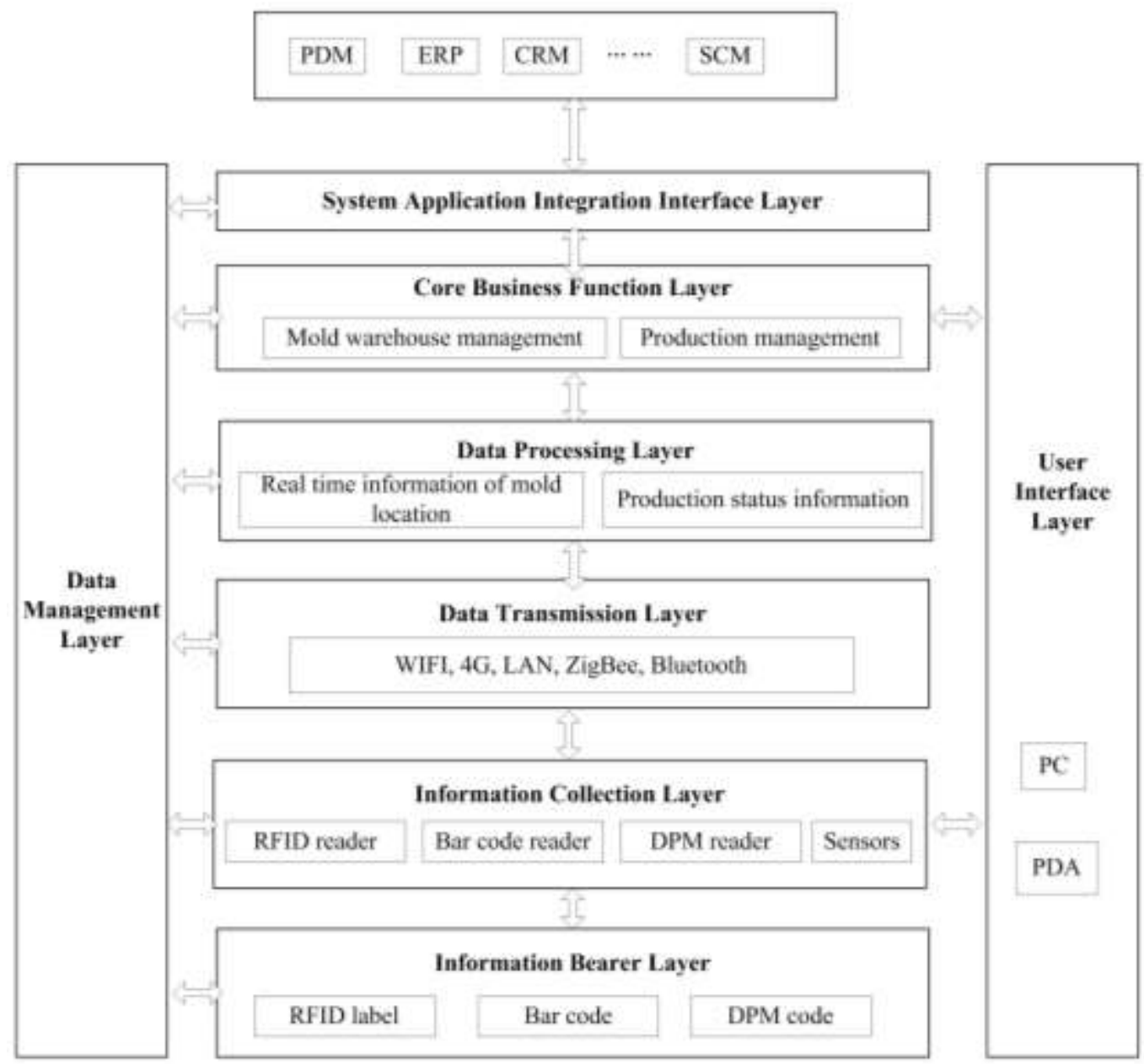

Figure 1. Mold management framework based on Internet of Things

\section{Automated Stereoscopic Mold Warehouse System Based on Internet of Things}

There are two main goals of constructing automated stereoscopic mold warehouse system [10]. One is to save storage space, shorten the mold handling time, improve the efficiency of handling. Another is to solve the current aluminum mold problems such as data disorder, management difficulties and other issues.

System Composition. The whole system is composed of two parts: hardware system and software system. The hardware equipment of automatic mold stereoscopic warehouse system mainly includes tiered mold warehouse facility and stacker. The warehouse is used to store the mold, and the stacker accesses the mold. The software system mainly includes mold management system and control system. The overall framework of automatic mold stereoscopic warehouse system is shown in Fig. 2.

Mold Management System. The main purpose of the system is to standardize the management of the mold. The main functions are as follows: 
The first is mold marking and recognition. If the management system wants to replace the existing manual working mode with paper records, all the mold should have a unique identification. At the same time, the mold information can be read and displayed by the corresponding equipment in the management system, and the administrator can view or issue instructions.

The second is information interface. The reading device of mold signal is connected with the management computer by the information interface. In addition, the management system also needs to communicate with the control system, send the storage instructions to the control system or receive the feedback information from the control system.

The third is loading and unloading management. The warehouse manager manages the delivery and storage of the mold according to the production needs of the workshop. It sends out loading or unloading instructions to the control system. After the control system receives the command, the stacker is controlled to complete the out or storage operation of the mold.

The fourth is location management. In the management system, the information of each library in the warehouse is recorded. And in the process of warehousing, library allocation is allocated according to certain principles. In addition, the administrator can also through the management system to quickly find the location information of each mold.

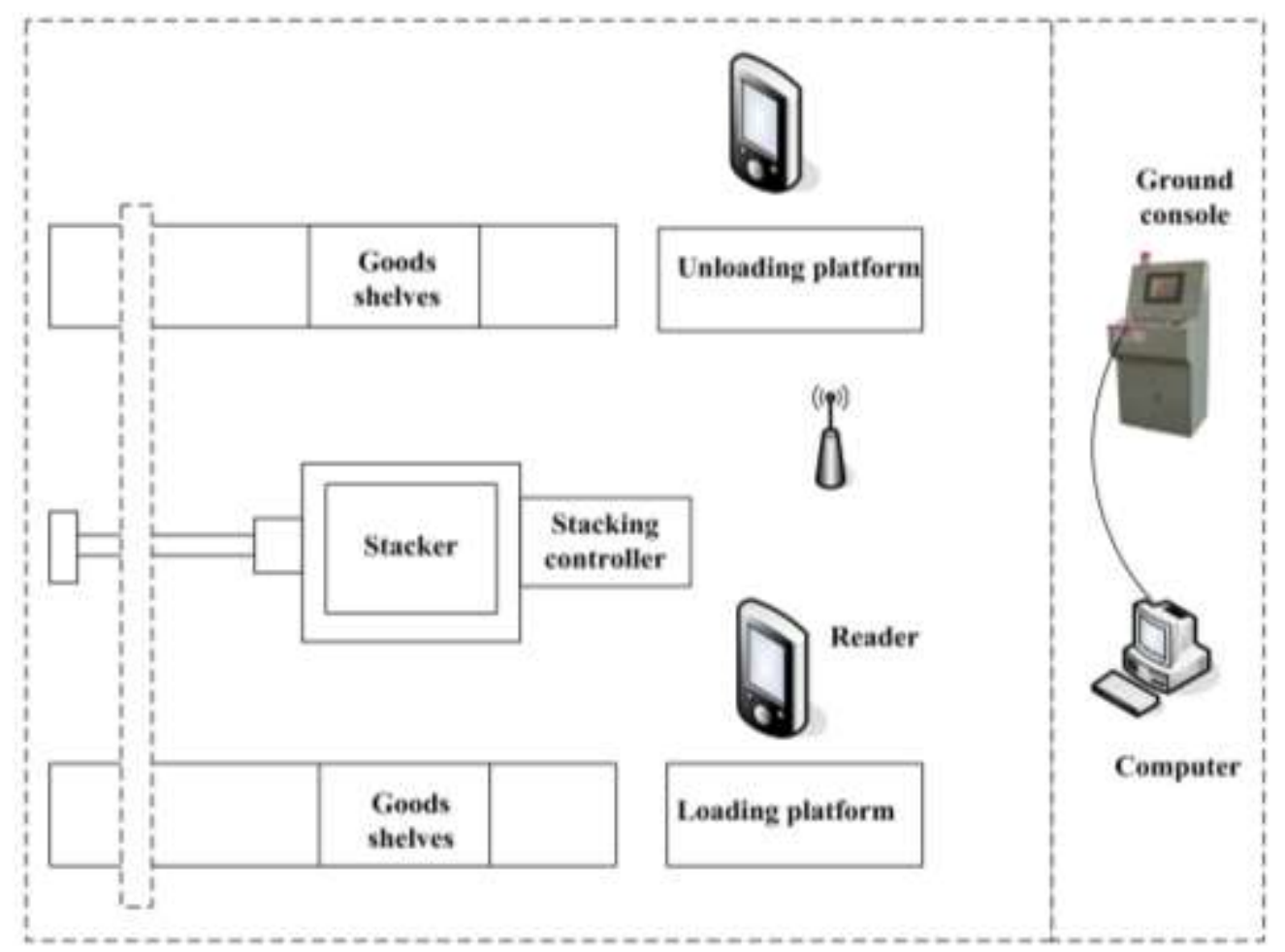

Figure 2. Sketch map of automatic mold stereoscopic warehouse system

Control System. Control system is the core of automatic mold warehouse system. The automatic loading and unloading operation of the mold is controlled by the control system. The functions of the control system are as follows:

The first is communication function. The control system should accept the information from the management computer, and feedback the job completion state. The second is the function of automatic access mold. It can automatically finish the operation of the mold in and out. The third is that it can coordinate the control of stacker and storage station, according to the requirements of warehousing operation. The fourth is that it can control the touch screen, reflect the parameters of the system operation, operation status and alarm light information. Finally, by installing the manual button, it can complete the manual control of the stacker. 


\section{Conclusions}

This paper systematically studies the application technology of the Internet of things technology in the mold management of aluminum profile manufacturing enterprises. Firstly, the appropriate mold marking technology is studied. Because the mold is in high temperature during the extrusion process, it is not suitable to place the RFID tag on the mold all the time. The research in this paper shows that the combination of DPM technology and traditional lettering mark can make the aluminum profile mold readily identify with readers at any time. Secondly, this paper constructs an open, layered and extensible framework based on the existing Internet of things application framework and mold management function requirements. Finally, in order to reduce the space occupied by the mold and improve the management efficiency of the mold, this paper proposes an automated stereoscopic mold warehouse system based on the Internet of things. It can greatly reduce the labor intensity, reduce the error rate, and effectively improve the level of production management. The research results of this paper have been applied in Guangdong Xingfa Aluminum Co. Ltd., and achieved good economic benefits.

\section{Acknowledgements}

This work is completed under the support of the "Special fund of Guangdong information industry development: modern information service industry project in 2013" and "Guangdong Enterprise Technology Center Project in 2013 ".

\section{References}

[1] C. Luo, Research on Intelligent Design System for Aluminum Extrusion and the Key Technologies. (Ph.D. Zhongnan University, China 2004), 5-31. (In Chinese)

[2] X. Ma, Planning, Design and Application of Automatic Stereoscopic Warehouse for Aluminum Profile Extrusion Mold. Logistics \& Material Handling, Vol.22(2017),No.1,76-80.

[3] M.K. Ji, Research on the Management System of Internet of Things for the Mold Industry. (MS. Anhui University of Science and Technology, China 2016), 4-18. (In Chinese)

[4] J. Zhang, Research and Practice of Mold Management System based on Internet of Things. (MS. Wuhan University of Science and Technology, China 2013), 10-30. (In Chinese)

[5] S.L. Ye, J.Q. Liu, J.R. Wu, The Application of PIC Single Chips in Mold Bar Code Identification System. Journal of Guangdong University of Technology, Vol.26 (2009), No.2, 94-97.

[6] W.L. Wang, J.B. Zhang, Research on Injection Mold Management System Based on RFID. China Mechanical Engineering, Vol.22 (2011), No.1, 65-68.

[7] G.J. Zhen, Application of DPM Technology in Special Part Marking. Mechanical Engineer, Vol.44 (2016), No.2, 152-154.

[8] C.Y. Wang, J.C. Zhang, 2D Bar Code Recognition Marking in Metal Parts. Journal of Computer Applications, Vol.32 (2012),No.11, 3210-3213.

[9] W. Song, W.F. Li, Y.H. Ge, Research on Mold Management System Based on the Technologies of Internet of Things. Journal of Wuhan University of Technology, Vol.34 (2012), No.11, 139-143.

[10] Q. Xu, Design of Automatic Control and Management System for Automated Storage and Retrieval System of Injection Mold. (MS. Nanjing University of Science and Technology, China 2016), 14-38. (In Chinese) 